\title{
A ANPUR E A CONSTRUÇÃO DO CAMPO CIENTÍFICO BRASILEIRO (2007-2009)
}

\author{
Edna Castro
}

\section{INTRODUÇÃO}

O objetivo deste artigo é refletir sobre uma parte da trajetória da ANPUR transcorrida na Gestâo 2007-2009, quando estive na direção da instituição, como sua presidente. Uma escrita com o distanciamento de cinco anos que provavelmente carrega omissôes indesejadas, mas permite um balanço mais longo do papel dessa Associação na construção do campo científico brasileiro.

A Associação Nacional de Pós-Graduação e Pesquisa em Planejamento Urbano e Regional (ANPUR) tornou-se, ao longo de seus 30 anos de existência, uma entidade científica consolidada e com desempenho acadêmico reconhecido no campo intelectual brasileiro e internacional. No correr dessas décadas a pesquisa e a pós-graduação sobre estudos urbanos e regionais no país teve extraordinário desenvolvimento, seja na conformação dos conteúdos programáticos, na ampliação das linhas de pesquisa, na redefinição de abordagens teóricas e metodológicas e no tratamento de temas tradicionais da área ao lado de outros emergentes que foram gradativamente sendo incorporados. Houve também uma ampliação de temáticas para pesquisas e para intervençáo ou extensão universitária. Como resultado, cresceu consideravelmente a produção científica e a formação de mestres e doutores. A institucionalização da pesquisa e da pós-graduação interferiu positivamente nesse aumento da produção de conhecimento nos centros de pesquisa e pós-graduação filiados à ANPUR e na publicação de livros e de artigos em revistas especializadas. Assim, a ANPUR contribuiu notavelmente com o movimento nacional de institucionalização e fortalecimento do sistema de ciência, tecnologia e inovação.

A trajetória dos estudos urbanos e regionais no Brasil foi a do entendimento de situaçôes de urgência, de interesse social e de demanda nacional ao lado de interpretaçôes teóricas sobre o próprio campo temático. Enfim, uma agenda voltada às questôes fundamentais da sociedade no contexto político de suas contradiçôes reais, de suas desigualdades sociais, de classe, de gênero, de raça e de etnia, que se atualizam continuamente no espaço urbano e regional. Esse campo amplo de pesquisas esteve presente também no debate teórico que foi crucial no seio da área de humanidades e de ciências sociais aplicadas, uma vez que, no correr dessas décadas, teorias, conceitos, categorias e temas foram colocadas em questão, revisitados e reinterpretados. Em consequência de situaçôes emergentes na dinâmica social, política e econômica do pais, outros processos e questóes se impuseram ao conhecimento. Como também se tornou necessária a revisão de paradigmas. O campo intelectual, enquanto um campo relacional, caracteriza-se justamente por esse embate teórico que se trava entre agentes sociais e institucionais, disputa de ideias na construção do conhecimento não alheia às estruturas de poder, e aos jogos políticos, que atravessam a sociedade. 
Gostaria de ressaltar que meu envolvimento maior com a instituiçáo começou na gestão 2005-2007, quando era presidente da ANPUR nossa colega Ana Fernandes (UFBA). Ao ser eleita membro de sua Diretoria e aprovado, em Assembleia Geral ocorrida durante o XI Encontro Nacional da ANPUR (ENANPUR), em Salvador, que o próximo ENANPUR seria em Belém, evidentemente estava depositada no Núcleo de Altos Estudos Amazônicos da Universidade Federal do Pará (NAEA/ UFPA), e em mim como membro da Diretoria, a incumbência de coordenar a organização do XII Encontro Nacional. Uma dádiva certamente de trabalho e tensão, embora com os louros do capital acadêmico. Sua realização foi para mim um aprendizado e uma imersão sobre a associação, os programas filiados e os grupos de pesquisa e de trabalho espalhados Brasil afora. Por essa razão, faço, neste texto, uma breve recapitulação do trabalho para receber o XII Encontro em Belém, com suas atividades tradicionais referidas ao formato dos encontros nacionais ou aquelas que inserimos na programação, como os Seminários - Imagem, Literatura e Pesquisa na Amazônia; Turismo, Lazer e Planejamento Urbano e Regional-, a Mostra de Filmes no Cine Olympia seguida de debates e as Excursóes Urbanas na cidade de Belém. Além do apoio dos colegas da UFPA (geografia, arquitetura, sociologia, economia e turismo), somos gratos à parceria bastante próxima com a então Diretoria da ANPUR, sobretudo com sua Presidente, Ana Fernandes.

\section{DIRETORIA DA GESTÃO 2007-2009}

Para o mandato 2007-2009, a Diretoria eleita no XII Encontro Nacional, em Belém, foi composta de Edna Maria Ramos de Castro - Presidente (UFPA), José Júlio Lima - Secretário Executivo (UFPA), Luiz Eduardo Aragón - Secretário Adjunto (UFPA) e tendo como Diretores Regionais Leila Christina Dias (UFSC), Roberto Luís Monte-Mór (UFMG) e Adauto Cardoso (UFRJ). O Conselho Fiscal foi formado pelos colegas Brasilmar Nunes (UnB), Renato Anelli (USP) e João Rovati (UFRGS). Cabe ressaltar que o Editor da Revista Brasileira de Estudos Urbanos e Regionais, cargo até então exercido por Henri Acserald (UFRJ), foi repassado durante o XII Encontro, em Belém, para Geraldo Magela Costa (UFMG), que permaneceu neste e em parte do mandato da diretoria subsequente. Ressalte-se que todos os membros da Diretoria assumiram diferentes atividades de interesse da ANPUR no transcorrer desses dois anos. O perfil de nomes e instituiçóes da diretoria atendia, assim, a uma prática cara à ANPUR, embora nem sempre conseguida, de obter uma representação próxima de sua diversidade temática, disciplinar, institucional e regional.

Ao longo dos últimos 30 anos, houve efetivamente a construção dessa área de conhecimento no Brasil. Não se trata de uma disciplina, mas da articulação de várias disciplinas - arquitetura e urbanismo, sociologia, geografia, economia, demografia, direito, turismo, entre outras - com objetivos convergentes para pensar a problemática urbana e regional, especialmente no país, o que requer, necessariamente, uma perspectiva interdisciplinar e um olhar construído a partir de temáticas transversais.

De fato, a área de planejamento urbano e regional (PUR) tem efetivamente forte interface com outras áreas, marcada por práticas interdisciplinares. Faço essa observação para as ciências sociais aplicadas uma vez que elas são estruturantes na área PUR, como também na Arquitetura e Urbanismo, com suas vertentes mais próximas às hu- 
manidades e aos fundamentos teóricos do entendimento da relaçáo entre espaço, política e sociedade. Esse corpo teórico-temático se desenvolveu expressivamente nesses 30 anos. Observa-se na atualidade a expansão da pós-graduação em planejamento urbano e regional por todo o país, alcançando um nível extraordinário de interiorização.

Com a crítica ao planejamento, alguns programas se deslocaram para o debate sobre desenvolvimento. Mas que na realidade são estudos de processos, análises de dinâmicas conformadas a uma perspectiva crítica do campo do desenvolvimento e de suas relaçôes com a economia e a política. Mas essas questôes já estavam postas há alguns anos, conforme os registros dos debates ocorridos por exemplo no IV Seminário de Avaliação do Ensino e Pesquisa em Planejamento Urbano e Regional, ocorrido em Belém.

\section{PLANEJAMENTO URBANO E REGIONAL: INSTITUCIONALIDADE, PESQUISA E PÓS-GRADUAÇÃo}

Os institutos e centros de pesquisa que surgiram nos anos 1960 em várias regiōes do Brasil, e em diversas áreas, desempenharam um papel absolutamente fundamental na construçáo da vida acadêmica brasileira. Inventaram experiências e arranjos para poderem realizar pesquisas e formar profissionais em meio a grandes restriçôes de recursos financeiros. Muitos programas tiveram primeiro, em suas trajetórias, a criação de cursos de especialização, depois o mestrado e, na maior parte dos casos, esperaram mais de cinco anos para iniciarem o doutorado. Esses Centros, Institutos e Programas criaram e institucionalizaram um padrão de Associaçóes Científicas Nacionais, contexto no qual surge a ANPUR, que se propóe a desenvolver uma área nova, formada pelos estudos e intervençôes na área do urbano e do regional e de suas interaçôes. A ANPUR resulta da iniciativa e do interesse de um conjunto de instituiçóes, de professores e de pesquisadores dos programas de pós-graduação de um dado campo de estudos na área do planejamento regional, urbano e habitacional. Há um reconhecimento da necessidade de criar balanços da produção científica, entâo em curso, e criar uma agenda de pesquisas substantiva e prospectiva quanto a temas teóricos, metodológicos e sobre as próprias condiçôes da produção do conhecimento na área.

Segundo a ata de fundaçáo da ANPUR, datada de 8 de junho de 1983, cinco programas de pós-graduação, que eram todos da área de planejamento urbano e/ou regional, participaram de sua fundação: Curso de Mestrado em Desenvolvimento Urbano da Universidade Federal de Pernambuco (MDU/UFPE), Curso de Mestrado em Planejamento Urbano e Regional da Universidade Federal do Rio de Janeiro (PUR/ UFRJ) Curso de Mestrado em Estruturas Ambientais Urbanas da Faculdade de Arquitetura e Urbanismo da Universidade de São Paulo (FAU/USP), Curso de Mestrado em Planejamento Urbano da Fundação Universidade de Brasília (UnB) e Programa de Mestrado em Planejamento Urbano e Regional da Universidade Federal do Rio Grande do Sul (PROPUR/UFRGS). No entanto, três anos depois, em junho de 1986, a assembleia realizada durante o primeiro Encontro Nacional da ANPUR, ocorrido em Nova Friburgo, no estado do Rio de Janeiro, organizado a partir de reuniōes entre os programas filiados e órgãos de fomento à pesquisa, aprovou o ingresso de mais três novos membros. Estes foram o Núcleo de Altos Estudos Amazônicos da Universi- 
dade Federal do Pará (NAEA/UFPA), que oferecia o Mestrado em Planejamento do Desenvolvimento/PLADES, o Centro de Desenvolvimento e Planejamento Regional da Universidade Federal de Minas Gerais (CEDEPLAR/UFMG) e o Mestrado em Arquitetura e Urbanismo da Universidade Federal da Bahia (UFBA). São todos eles vinculados a universidades federais e se constituíram em torno da implantação de uma pós-graduação. Vários deles têm perfil de centros de pesquisas, com um interesse temático, não disciplinar.

Os centros e os programas de pós-graduação mais antigos filiados à ANPUR datam dos anos 1970, crescendo no correr dos anos 1980 e 1990, o que permitiu a consolidaçáo dos programas e a definição de um modo de funcionamento, ao mesmo tempo que se consolida o sistema de pesquisa e de pós-graduaçáo no país. Esses programas pioneiros tiveram um papel de irradiação da pesquisa e da pós-graduação para outras universidades, sobretudo por formar seus mestres e doutores. No final do século e, sobretudo, no início do século XXI, houve um surpreendente crescimento dos cursos de mestrado e de doutorado da área de planejamento e desenvolvimento urbano e regional. Atualmente estáo filiados à ANPUR 64 programas que recobrem uma ampla área que nomeamos de estudos urbanos e regionais, mas com certa diversidade: planejamento urbano e regional, desenvolvimento regional, arquitetura, urbanismo, demografia, geografia, sociologia, administração pública, economia, políticas públicas, turismo, entre outras.

O surgimento de novos programas provoca, junto com as mudanças na regulação do sistema de ciência e tecnologia no país e a expansão da pós-graduação, um movimento de fortalecimento de uns, de desestabilização ou reestruturaçáo de outros, tendo os novos programas o propósito também de ocupar lugar e se tornar programa consolidado. Essa tensão de crescimento conforma a atualidade da área de planejamento urbano e regional.

A ANPUR teve sem dúvida um papel histórico importante na formação e constituição dessa área de conhecimento enquanto agente no processo de progressiva institucionalização da área. Estimulou a criação de novos programas de pós-graduação pari passu a sua vida acadêmica. Realizou os Encontros Nacionais a cada dois anos e apoiou os diversos eventos organizados anualmente pelos centros e programas a ela filiados. Todos esses espaços se revelaram importantes para a circulação de ideias, difusão de resultados de pesquisa e formulação de novas agendas de pesquisa com projetos relevantes para as áreas de política de ciência e tecnologia e de desenvolvimento urbano e regional. Sua participação ativa nos Comitês de Avaliação de Pesquisa e de Pós-graduação, tais como as agências de fomento Conselho Nacional de Desenvolvimento Científico e Tecnológico (CNPq), Coordenação de Aperfeiçoamento de Pessoal de Nível Superior (CAPES), Financiadora de Estudos e Projetos (FINEP) e Fundaçóes de Amparo à Pesquisa (FAPs), ou ainda sua articulação com outras associaçóes nacionais e internacionais, mostram o papel protagonista que ocupou na institucionalização da área temática de planejamento/desenvolvimento urbano e regional no país.

O sistema de pós-graduação e de pesquisa mantém ainda fortes desequilíbrios em relação ao financiamento entre áreas e entre estruturas e competências regionais que geram efeitos sobre o acesso a bolsas, aos recursos para pesquisa e a outras açóes demandantes de fomento. As áreas de humanidades e ciências sociais aplicadas sempre estiveram na faixa cinzenta do financiamento público 
ensejando, em momentos diferentes, a ação conjunta de associaçôes cientificas, como expressão coletiva de demandas, junto sobretudo ao CNPq e à CAPES. Em vários Encontros e reunióes promovidas pela ANPUR, foi objeto de discussão a proposta de uma política de pesquisa para a área capaz de assegurar maior rigor na pesquisa e na formação de pesquisadores, fazendo jus às discussôes sobre a formação acadêmica e profissional. Iniciativas conjuntas com outras associaçóes de humanidades e ciências sociais foram tomadas também em gestôes anteriores e posteriores a nossa. Finalmente, em 2014, o CNPq, como resposta à mobilização dessas áreas a partir da constituição do Fórum de Ciências Humanas reunido em vários encontros da Sociedade Brasileira para o Progresso da Ciência (SBPC), da Associação Nacional de Pós-Graduação e Pesquisa em Ciências Sociais (ANPO$\mathrm{CS}$ ) e da Associação Brasileira de Antropologia (ABA), e que culminou com o Seminário do Fórum no CNPq, no qual esteve presente a ANPUR, na pessoa de sua Presidente, Virgínia Pontual (UFPE), tomou a decisão, finalmente, de criar uma Área de Humanidades e Ciências Sociais Aplicadas.

\section{PLANEJAMENTO/DESENVOLVIMENTO URBANO E REGIONAL - DIÁLOGOS E INTERLOCUÇÕES}

\section{SESSões TemÁticas}

O XII Encontro Nacional da ANPUR, em Belém, surpreendeu pela diversidade temática e pelo nível dos debates, tendo ultrapassando 1.000 inscriçóes de trabalhos. Destes, 359 trabalhos completos foram aceitos para serem apresentados nas Sessóes Temáticas. O encontro contou ainda com a realização de 48 Sessóes Livres, em que foram divulgados resultados de pesquisa em andamento ou concluídas, no Brasil ou no exterior. Espaços de reflexão e produção de novas questóes sobre os desafios do espaço urbano e regional, da sociedade, da economia e da política, perspectivas de análise em discussão que tiveram provavelmente desdobramentos nos programas de pesquisa e de formação de mestrado e doutorado.

O Encontro teve sete Sessôes Temáticas, das quais observa-se maior presença de temas voltados aos estudos urbanos, porém associados a dinâmicas sociais, econômicas e políticas do debate sobre desenvolvimento que sobressai ao de planejamento. São elas: 1 - Gestão Urbana e regional: modelos, práticas e implicações, coordenada por José Julio Lima (UFPA) e Roberto Monte-Mór (UFMG); 2 - Rede Urbana e Estrutura Territorial, coordenada por Jan Bitoun (UFPE) e Maria Flora Gonçalves (UNICAMP); 3 - Forma e Dinâmica Intraurbana, coordenada por Luciana Lago (IPPUR) e Ângelo Serpa (UFBA); 4 - História, Cidade e Urbanismo, coordenada por Ivone Salgado (PUC-Campinas) e Eloisa Petti (UFBA); 5 - Território, Conflitos e Gestão Ambiental, coordenada por Henri Acserald (UFRJ) e Rogério Haesbaert (UFF); 6 - Cidade, Cultura e Sociabilidade, coordenada por Brasilmar Ferreira (UnB) e Ligia Simonian (UFPA); 7 - Amazônia no Cenário Sul-americano, coordenada por José Aldemir de Oliveira (UFAM) e Luis Aragón Vaca (UFPA).

A discussão do que é o planejamento urbano e regional tem estado presente em todos os momentos relevantes do debate acadêmico, até mesmo como forma de 
atualização. Tem interrogado o sentido da relação ensino e pesquisa, do rigor da pesquisa, das escolhas de metodologias e dos resultados diante da proximidade do tema e às formulaçóes políticas. A sistematização desse campo é pensada na relação com as transformaçôes na sociedade, na economia, no papel do Estado e na crescente racionalização do mundo. Haveria talvez uma retomada de ideias intervencionistas do Estado ou se estaria diante de outras abordagens teóricas e metodológicas que revelem questôes emergentes? Qual o lugar do planejamento crítico hoje? Ele não demarcou uma experiência no Brasil que é relevante e reconhecida em outros países como uma contribuição nossa ao tema? Seria uma forma de exequibilidade do planejamento ou de afirmação do conhecimento científico para além da ordem política e ideológica? Essas e outras questóes permanecem pertinentes e vivas no debate atual.

\section{Mesas Redondas e Produção de DVDS}

No XII ENANPUR foram organizadas 8 mesas, redondas das quais seis foram transformadas em vídeos. Por razóes técnicas lamentavelmente três ficaram fora do projeto Vídeos-ANPUR, que são a MR - Integração Sul-americana, Relaçôes Transfronteiriças e Desenvolvimento Urbano e Regional, coordenada por Edna Castro (UFPA) e tendo como expositores Alírio Martinez (UCV/OTCA), Lia Machado (UFRJ), Henri Acselrad (UFRJ) e Hélène Rivière D'Arc (CNRS/IHEAL); a MR - Violência e Cidades Brasileiras: o que falar das Politicas Públicas?, coordenada por Elson Manoel Pereira (UFSC) e sendo seus expositores Alba Zaluar (IUPERJ), Kátia Mendonça (UFPA), Lourdes Bandeira (UnB) e Maria Elvira Sá (UFPA); e também a MR - Os Desafios da Educação Superior no Brasil: Novas Arquiteturas Acadêmicas, tendo como coordenador Carlos Vainer (UFRJ) e expositores Naomar de Almeida Filho (Reitor da UFBA) e Zélia Amador (Vice-Reitora da UFPA). O conjunto de vídeos produzidos nos permite rever as exposiçôes e os debates.

No projeto Videos-ANPUR, as mesas redondas editadas foram as seguintes:

MR 1 - O PAC e seus Impactos na Política de Desenvolvimento Urbano e Regional, participando como coordenadora Ana Fernandes, presidente da ANPUR na ocasião, e expositores Edgard Porto (SEI), Carlos Vainer (UFRJ), Ermínia Maricato (USP), Claudio Puty (UFPA), Miguel Lobato (Mov. Nac. de Luta pela Moradia);

MR 2 - Metrópole, Reforma Urbana e Desenvolvimento Nacional, coordenada por Luis César de Queiroz (UFRJ) e os expositores Carlos de Matos (PUC-Chile), Clélio Campolina (UFMG) e José Julio Lima (UFPA);

MR 3 - Planejamento Territorial: uma retomada do papel do Estado no Desenvolvimento Urbano e Regional, coordenada por Maurílio Monteiro (UFPA e tendo como expositores Jan Bitoun (UFPE), Brasilmar Ferreira (UnB), Aldomar Arnaldo Ruckert (UFRGS) e Armin Mathis (UFPA);

MR 4 - Por uma Politica Nacional de Pesquisa em Desenvolvimento Urbano e Regional, coordenada por Heloisa Costa (UFMG) e tendo como expositores Ana Fernandes (UFBA), Eglaísa Cunha (MCidades), Ermínia Maricato (USP), Norma Lacerda (UFPE), Raquel Rolnik (PUC-Campinas), Marilena Correa (UFAM), Ana Clara Torres (UFRJ) e Edmilson Rodrigues (UFRA);

MR 5 - Conflitos e Territorialidades na Amazônia, coordenada por Rosa Acevedo (UFPA) e tendo como expositores Roberto Araujo (MPEG), Alfredo Wagner de Almeida (UFAM), Marcelo Carneiro (UFMA) e Marco Antônio Teixeira (UFRR); 
MR 6 - Mudanças Climáticas e o papel da Floresta Amazônica, coordenada por Everaldo Barreiros Souza (UFPA) e os expositores foram Carlos Nobre (INPE), Emilio Moran (Indiana University) e Leandro Ferreira (MPEG).

\section{SEMINÁRIOS, FÓRUNS E WORKSHOPS}

Os Seminários, Fóruns e Workshops organizados pelos programas filiados, propostos e aprovados na Assembleia Geral realizada em maio de 2007, fazem parte da programação anual da ANPUR. Significa oportunidade singular e atendem ao papel de construção institucional e muitas vezes redefinição de sentidos, seja pelo diálogo entre programas sobre as inquietaçôes teóricas, metodológicas e de ordem da intervenção prática, seja pela reflexão sobre a dinâmica do sistema de pós-graduação e pesquisa no país.

Na gestão 2007-2009 foi realizado ainda o IV Seminário de Avaliação de Ensino e Pesquisa em Planejamento Urbano e Regional (SEPEPUR), em Belém, de 23 a 24 de outubro de 2008, no Hotel Hilton, que permitiu atualizar o diálogo entre centros e programas.

Os eventos ocorridos no correr de 2007-2009 foram os seguintes:

1 - IV Seminário de Avaliação do Ensino e Pesquisa em Planejamento Urbano e Regional Realização: ANPUR. Belém, 23 e 24 de outubro de 2008;

2 - XIII ENANPUR - Encontro Nacional da ANPUR

Realização: ANPUR, Florianópolis, 25 a 29 de maio de 2009;

3 - Seminário Nacional sobre o Tratamento de Áreas de Preservação Permanente em Meio Urbano e Restriçôes Ambientais ao Parcelamento do Solo

Realização: FAU-USP, PUC-Campinas, ANAMA e ANPUR, São Paulo, 04 a 07 de setembro de 2007;

4 - Colóquio Internacional "Os Desafios Urbanos no Brasil e na África do Sul" - Construindo uma Agenda para a Cooperação em Ensino e Pesquisa

Realização: IPPUR/UFRJ e LABHAB/FAU/USP, Rio de Janeiro, 9 a 12 de setembro de 2007;

5 - II Encontro Brasileiro de Ciências Sociais e Barragens

Realização: IGEO/UFBA, IPPUR/UFRJ, UFRB, UNEB e UCSal, Salvador, 19 a 22 de novembro de 2007;

6 - I Encuentro Latinoamericano Ciencias Sociales y Represas Realização: IGEO/UFBA, IPPUR/UFRJ, UFRB, UNEB e UCSal, Salvador, 19 a 22 de novembro de 2007;

7 - XII Seminário sobre a Economia Mineira

Realização: CEDEPLAR/UFMG, Diamantina, 26 a 30 de agosto de 2008;

8 - X Seminário de História da Cidade e do Urbanismo. Realização: MDU/UFPE, PPGAU/UFRN, CECI, DEHA/UFAL e PPGEUA/ UFPB, Recife, 08 a 10 de outubro de 2008;

9 - Seminário Amazônia e Fronteiras do Conhecimento Realização: NAEA/UFPA. Belém, 09 a 11 de dezembro de 2008;

10 - Eventos ANPUR/NAEA no Fórum Social Mundial Realização: ANPUR e NAEA/UFPA, Belém, 28 a 30 de janeiro de 2009:

a) Painel Políticas Públicas e Sustentabilidade na Resex Marinha Mãe Grande de Curuçá (Pará); 
b) Conferência de Michel Lowy - França - Ecosocialismo;

c) Seminário-Debate - Amazônia Regiáo Universal e Teatro do Mundo. Expositores: Willi Bolle, Edna Castro, Alfredo Wagner de Almeida, Neusa Pressler;

d) Painel - Conhecimentos tradicionais no mundo globalizado: oportunidades de intercâmbio entre sociedade civil, academia e área de políticas públicas no contexto Sul-Sul;

e) Seminário - Cidades da Pan-Amazônia: configurações e diversidade Social na América do Sul - Coordenação: Edna Castro.

Um rápido balanço dos debates nos eventos da ANPUR indicam, em síntese, ser alta a produtividade da área, embora os critérios de valorização dos periódicos nem sempre retratem o perfil desses programas. Também foram aperfeiçoados os diretórios de pesquisa, os mecanismos de avaliaçáo de periódicos, de livros e de anais. Enfim, há grande esforço de construção da área, que apesar da tradiçáo diferente de como se constituíram as áreas de Humanidades e Ciências Sociais Aplicadas, em vários pontos, revelam as convergências.

No IV Seminário de Avaliação de Ensino e Pesquisa em Planejamento Urbano e Regional, realizado em Belém, foi reafirmada a importância de ser criado, junto às agências de fomento, um dispositivo tipo GT Cidades, com o objetivo de orientar os financiamentos na direção de temas centrais às áreas e linhas de pesquisa dos programas de pós-graduação. Todavia, essa ideia não deveria ser sumariamente associada à resoluçáo de velhos passivos no financiamento da pesquisa, mas uma resposta da formação e da pesquisa ao crescimento das cidades no país e ao agravamento dos problemas urbanos que exigem urgência e conhecimento.

Várias Sessôes Livres de Encontros Nacionais têm sugerido agendas de pesquisa com questôes de prioridade nacional e regional - sociais, urbanas, ambientais - face às desigualdades, às tensões e, sobretudo, à violência de várias ordens que tem transformado os espaços sociais, urbanos e regionais no país. Por isso a necessidade de definir critérios de avaliação com parâmetros de eficácia temática, interdisciplinar, de especificidades e ao mesmo tempo de convergências de cada subárea, dimensóes e iniciativas de construçâo do conhecimento e sua institucionalidade.

\section{PrÊMIOS ANPUR 2007}

No Encontro Nacional de 2007, em Belém, a ANPUR outorgou as premiaçôes a autores e, conseguintemente, a programas. O VI Prêmio Brasileiro de "Política de Planejamento Urbano e Regional", na categoria Dissertação de Mestrado, teve como júri Norma Lacerda Gonçalves (Presidente) - UPFE, Lúcia Maria Machado Bógus PUC-SP, Margareth Aparecida Campos da Silva Pereira - UFRJ, Ana Fani Alessandri Carlos - USP e Nádia Somekh - UPM, que premiou com o primeiro lugar a autora Silvana Lamenha Lins Olivieri - PPG-AU/UFBA, com a dissertação Quando o cinema vira urbanismo: o documentário como ferramenta de abordagem da cidade (Orientadora: Profa. Paola Berenstein Jacques).

O júri atribuiu Mençóes Honrosas aos autores das dissertaçôes: Aline Figueiredo de Albuquerque - FAU/USP, com a dissertação A questão habitacional em Curitiba: o enigma da "cidade-modelo" (Orientador: Prof. João Sette Whitaker Ferreira); Rosane Piccolo Loreto - MDU/UFPE, intitulada Paraíso \& Martírios: história de destruição 
de artefatos urbanos e arquitetônicos no Recife (Orientadora: Profa. Virgínia Pontual); Eloi Martins Senhoras - PPGGeo/UNICAMP, com a dissertação Regionalismo transnacional e integração física: um estudo sobre a iniciativa de integração da infraestrutura sul-americana (Orientadora: Profa. Claudete de Castro Silva Vitte); Evelyne Labanca Corrêa de Araújo - MDU/UFPE, intitulada O laço que prende: um estudo sobre conservação integrada em metodologias de desenvolvimento local sustentável (Orientador: Prof. Sílvio Mendes Zancheti); Lucas Roosevelt Ferreira Linhares - CEDEPLAR/UFMG, com o trabalho As ideias fora do lugar e o lugar fora das ideias: o (sub)desenvolvimento sócio-econômico-espacial no Brasil e as possibilidades contemporâneas do seu planejamento (Orientador: Prof. Roberto Luís de Melo Monte-Mór); Maurício Brito e Cunha Valladares - PROURB/UFRJ, com o título Entre a natureza e o artifício: percepçôes e perspectivas nos projetos para parques urbanos e orlas fluviais (Orientadora: Profa. Ana Lúcia Nogueira de Paiva Brito).

Na categoria Tese de Doutorado, o júri foi composto de Ana Cristina Fernandes (Presidente) - UFPE, Maria do Livramento Miranda Clementino - UFRN, Vera Lucia Ferreira Motta Rezende - UFF, Olga Lucia Castreghini de Freitas Firkowski UFPR e Jan Bitoun - UFPE. O júri aprovou para primeiro lugar a tese de José Clewton do Nascimento - PPG-AU/UFBA, com o título (Re)Descobriram o Ceará? Representaçóes dos sitios históricos de Icó e Sobral: entre Areal e Patrimônio Nacional. Também contemplou com Menção Honrosa as autoras Chélen Fischer Lemos - IPPUR/UFRJ, com a tese $O$ processo sociotécnico de eletrificação na Amazônia: articulaçóes e contradiçóes entre estado, capital e território (1890 a 1990), e Thais de Bhanthumghinda Portela - PPG-AU/UFBA, intitulada O urbanismo e o candomblé: sobre cultura e produção do espaço público urbano contemporâneo.

No IV Prêmio Milton Santos, na categoria Artigo, a ANPUR contou com a colaboração do júri formado por Geraldo Magela Costa (Presidente) - UFMG, Ana Maria Fernandes - UFBA, Lilian Fessler Vaz - UFRJ, Jupira Gomes de Mendonça - UFMG, Luciana Corrêa do Lago - UFRJ e Carlos Antônio Brandão - UNICAMP. O júri agraciou com o Prêmio Milton Santos o artigo de Pedro Abramo Campos - IPPUR/ UFRJ, A Cidade Com-Fusa: A mão inoxidável do mercado e a produção da estrutura urbana nas grandes metrópoles Latino-Americanas, publicado na Revista Brasileira de Estudos Urbanos e Regionais, v. 9, n. 2, de novembro 2007. E atribuiu Menção Honrosa ao artigo de Sérgio Manuel Merêncio Martins - Geografia/UFMG, intitulado Urbanização e Violência: reflexóes a partir do livro e do filme Cidade de Deus, publicado na revista GEOgraphia, ano IX - n. 18, de dezembro 2007.

$\mathrm{Na}$ categoria Livro, recebeu o Prêmio Milton Santos a autora Fania Fridman - IPPUR/UFRJ, com o livro Paisagem Estrangeira: memórias de um bairro judeu no Rio de Janeiro - Rio de Janeiro: FAPERJ/CNPq/Casa da Palavra, 2007. E receberam Menção Honrosa Denise Xavier de Mendonça - EESC/USP, com o livro Arquitetura Metropolitana - São Paulo: FAPESP/Annablume, 2007; e Juliano Aparecido Pereira EESC/USP, com Lina Bo Bardi - Bahia, 1958-1964 - Uberlândia: EDUFU, 2008.

\section{PUBLICAÇÕES DA ANPUR}

A Revista Brasileira de Estudos Urbanos e Regionais (RBEUR) é a principal publicação da ANPUR. Na gestão 2007 a 2009 o editor responsável foi Geraldo Magela Costa, que contou com a colaboração da Comissão Editorial, formada num primeiro 
momento por Leila Christina Dias (UFSC), Lilian Fessler Vaz (UFRJ) e Maria Flora Gonçalves (UNICAMP) e, posteriormente, por Ana Fernandes (UFBA), Carlos Antônio Brandão (UNICAMP), Lilian Fessler Vaz (UFRJ) e Luciana Corrêa do Lago (UFRJ). Foram publicados no período dois volumes, ou seja, vol. 9 / no 1 e 2 e vol. 10 / no 1 e 2, contando com financiamento do CNPq e da própria ANPUR.

Com o apoio institucional da ANPUR, foi publicada a coletânea organizada por Silvio Lima Figueiredo (UFPA), intitulada Turismo, lazer e planejamento urbano e regional, Belém: NAEA/UFPA, 2009.

A primeira diretoria da ANPUR criou o Boletim Informativo, que divulgava as atividades e fazia o registro da memória da instituição, que se manteve, embora no correr do tempo tenha havido interrupçóes, mudanças nos formatos e nos seus conteúdos e, inclusive, na sua qualidade gráfica. Na nossa gestão foram feitos oito números, do 13 ao 20 , todos eles disponibilizados no site da instituição.

\section{EXPRESSÃO NACIONAL E INTERNACIONAL - A AMÉRICA LATINA NA TRADIÇÃO DA ANPUR}

É graças ao esforço coletivo de institucionalização das associaçôes científicas que se tem, no Brasil, maior sistematização da formação e da pesquisa que provavelmente em outros países da América Latina. Isso, apesar de se encontrar naqueles países, desde os anos 1960, experiências notáveis de centros de pesquisa e de formação profissional que se tornaram espaços de excelência na reflexão sobre a realidade nacional e latino -americana, como no México, no Chile, na Argentina, na Colômbia, no Equador e no Uruguai, entre outros. A tradição no campo das relaçôes latino-americanas faz parte da trajetória de diversos programas filiados à ANPUR, mas as interaçôes e experiências conjuntas de pesquisa e formação, capazes de fomentar estudos comparativos, mostram-se ainda residuais, com algumas exceções.

O Brasil viveu momentos relevantes no intercâmbio internacional, resultando na experiência plural dos profissionais que implantaram e consolidaram o nosso sistema de pós-graduação, como estudos de mestrado e doutorado feitos nos Estados Unidos e países europeus, notadamente França, Inglaterra e Alemanha. Houve, nos anos 1960 e 1970, um grande afluxo para o Chile, por motivos políticos e intelectuais, seja direcionado para a Comissão Econômica para a América Latina e o Caribe (CEPAL), para discutir temas de planejamento e desenvolvimento, para a Faculdade Latino-Americana de Ciências Sociais (FLACSO) ou outros centos e universidades no México e na Argentina.

Isso se reflete na formação de redes de pesquisa com amplitude internacional. O ENANPUR realizado em Porto Alegre definiu como tema do encontro Integraçáo latino-americana, incentivando o debate sobre a fronteira sul do país. Essa perspectiva internacional e latino-americana reaparece no encontro de Belém, que formulou como temática central a Integração sul americana, Fronteiras e Desenvolvimento Regional. Na mesma direção, houve uma Sessão Temática - intitulada Amazônia no Cenário Sul-Americano - pensada para estimular o tema e ao mesmo tempo como observatório sobre o estado da arte dos grupos de trabalho voltados a essa problemática no país. Esse acabou sendo um dos debates ressaltados nos eventos ocorridos durante a gestáo 2007-2009 e, na nossa avaliação, houve um avanço. Circulara como ideia a constru- 
ção de estratégias institucionais para a construção mais densa de um campo de estudos que abrisse novas perspectivas da reflexão sobre o Brasil e suas relaçôes com os países sul-americanos, e pesquisas comparativas com parceiros da América Latina.

Objetivando produzir não apenas um balanço da reflexão acadêmica mas postular uma afirmação política daquilo que a universidade tem de melhor, sua capacidade de pensar, de interpretar, de construir ideias e propor alternativas comprometidas com a sociedade, o XII Encontro Nacional constitui uma atividade de construção da área de estudos urbanos e regionais. E, na ocasiáo, propôs ao debate entender as mudanças por que passava a América Latina, que indicava ao meio acadêmico uma agenda de novas questóes urbanas e regionais que demandava reflexão e capacidade de resposta por parte de pesquisadores, planejadores e demais profissionais envolvidos com os programas de pós-graduação e pesquisa.

Efetivamente, no IV SEPEPUR, em Belém, os participantes insistiram na necessidade, como questáo de política acadêmica, de melhorar os espaços nos programas para as relaçôes internacionais, através de parcerias, redes e convênios. Neste cenário analisou as iniciativas e a orientação da esfera governamental dos Ministérios de Ciência, Tecnologia e Inovação e do Ministério da Educação, como aquelas que objetivavam induzir acordos com a comunidade dos países de língua portuguesa, explicitados em vários programas, a exemplo do Pró-África. A ANPUR, através de seus programas de pós-graduação e de pesquisa, participa de um número expressivo de redes de pesquisa e de parcerias com instituiçôes - nacionais e internacionais.

Os congressos mundiais sobre o tema de planejamento urbano e regional têm sido um lugar de reflexão e de análise dos avanços na institucionalização mundial da área. O Congresso do GPEAN é o principal evento internacional da área de planejamento, pois representa associaçóes científicas organizadas por continentes e países do mundo. A ANPUR faz parte dessa rede internacional de planejamento, da qual fazem parte as principais e mais representativas organizaçóes de pesquisa em planejamento urbano no mundo, que são: Associação de Escolas de Planejamento Americana - ASPI; Europeia - APERAU; ANPUR; ALEUP (México, Venezuela e Argentina); AAPS (Países Africanos); APSA (Ásia); ANZAPS (Austrália e Nova Zelândia). Essas associaçôes se reúnem a cada dois anos, a depender da pauta do encontro. O GPEAN publica a série de livros Diálogos de Planejamento Urbano e Regional, com resultados dos Congressos. Durante a Gestão 2007-2009, foram publicados artigos de docentes de programas da ANPUR e a Associação participou da Reunião do Coordinating Committee do GPEAN/AESOP, "Planning for the risk society", realizado em Nápoles-Itália, de 10 a 14 de julho de 2007. Estiveram presentes Roberto Monte-Mór e José Julio Lima.

O corpo editorial de suas publicações é compartilhado e os artigos publicados se originam de indicaçóes dos melhores trabalhos de eventos realizados pelas Associaçôes Científicas parceiras. Houve um crescimento da participação da ANPUR nesses congressos internacionais, mas ainda é muito restrito. A participação da ANPUR no GPEAN deve ser socializada entre os programas de pós-graduação filiados, objetivando ampliar sua visibilidade no plano internacional.

Ainda cabe ressaltar que nesse período houve um debate no seio dos programas sobre como se posicionar frente aos desafios de construir intercâmbios institucionais no âmbito da relação sul-sul, estimulada pelas agências de fomento através de editais. A relação sul-sul foi ressaltada na esfera governamental na primeira década deste século, orientando para editais Brasil X África com programas de vários Ministérios volta- 
dos a países da América do Sul. O debate se orientou para entender que é um campo tensionado pela política e parte de estratégias de influência geopolítica. Questōes levantadas - tais como qual o lugar da ANPUR na cooperação sul-sul? De que maneira se poderia pensar em abordagens, parcerias e pesquisas cooperativas? E para pensar o planejamento internacional? - foram retomadas nos encontros nacionais posteriores, como se observa em seus programas de mesas redondas e sessôes livres.

\section{ORDENAMENTO INSTITUCIONAL: O NOVO ESTATUTO DA ANPUR}

Essa foi uma das atividades administrativas de maior importância para a continuidade da ANPUR, considerando os impasses verificados no seu Estatuto, defasado pelas mudanças ocorridas na legislaçáo nacional que ordena o funcionamento de associaçóes dessa natureza. Para o novo estatuto foi contratado o serviço de um escritório de advocacia que o adequou aos dispositivos legais pertinentes, sendo o mesmo revisto inúmeras vezes pelo coletivo de colegas da Associação. Finalmente, discutido, reformulado e aprovado na Assembleia Geral Extraordinária que se reuniu durante o XIII Encontro da ANPUR, em Florianópolis, em maio de 2009.

$\mathrm{Na}$ esteira de acionar mecanismos para ampliar a institucionalidade da ANPUR, foi feita uma modernização do site e realizados, durante a gestão, investimentos na área de comunicação. Visava-se criar mais transparência, agilidade e espaço para divulgação online da Revista, das publicaçôes, disponibilizar o acesso aos DVDs e facilitar o trabalho da secretaria. A melhoria do site permitiu implementar alguns serviços, tais como comunicação mais rápida com os programas e cobrança das anuidades via Boleto Bancário.

Finalmente, cabe ressaltar que nesses 30 anos da ANPUR houve ampliação, em várias direçōes, de seu formato, acompanhando o movimento nacional de construção do campo científico. Mas trouxe também à reflexão novas questôes e velhos dilemas, neste caso o de transitar na tênue linha entre a pesquisa e a extensão, esta em função de demandas crescentes da sociedade ou da área governamental, quer seja para consultorias, elaboração de documentos, diagnósticos e formulação de planos diretores de açôes e intervençôes postos à área. Isso tem a ver com a concepção da ANPUR que, desde seus primórdios, sempre procurou manter e fomentar um compromisso político e social visando contribuir, ao fazer ciência, com a produção do conhecimento para uma sociedade cidadã, menos desigual e excludente.

Belém, novembro de 2014. 